\title{
Promoting Character At Institutions Of Higher Education And In Their Academic Units
}

Harrison McCraw, (E-mail: jmccraw@westga.edu), State University of West Georgia Ara Volkan, (E-mail: avolkan@fgcu.edu), Florida Gulf Coast University

Bruce Bird, (E-mail: bbird@westga.edu), State University of West Georgia

As a child growing up in Lower Alabama (LA), on Saturday my mother would treat me to a day at the "picture show up the street" (25 cents admission). I would stay at the "show" from 9:30 AM to 2:30 PM and would delight in 3 cartoons, an installment of a serial, and 3 cowboy movies. In almost every movie, "Roy, Gene, Lash, and the Lone Ranger" never seemed to hesitate when confronted with decisions that required moral or physical courage. Although the bad guys had plenty of physical courage (after all, they were shooting real bullets), they always seemed to take the "easy way out" and pursue the "quick fix" (robbing banks, trains, and stage coaches, stealing horses and cattle, and drinking hard liquor straight out of the bottle) in order to become rich, powerful, and famous. Character, or the lack of it, was plainly on display...JHM

\begin{abstract}
Employers are highly interested in the character traits of college graduates. They recognize that these attributes will be an important determinant in the degree of success their organizations will experience. Unfortunately, a significant proportion of students enrolled in public institutions of higher education are not prepared academically, behaviorally, or emotionally for the college experience. In addition, lack of academic integrity on campus poses its own set of problems. Employers also realize that special ethical obligations exist for employees with financial reporting responsibilities. Accountants are required to generate accurate and timely information to stakeholders both inside and outside of the organization. Employers are keenly interested in hiring accountants who are willing to assume the responsibility for promoting integrity throughout the firm. To compete in today's educational market place, many institutions of higher learning focus upon beautifully manicured grounds, impressively designed and technologically advanced buildings, and learned faculty. Alternatively, do these institutions dedicate adequate resources and expend the necessary levels of energies to promote character and other desirable traits in students? Isn't character just as important in public higher education as critical analysis or technical skills? This article proposes the development and use of creeds by departments, colleges, and/or universities to underscore the importance of character, scholarship, and performance to students. A creed is a statement of institutional expectations, beliefs, principles, and values. It is a public pronouncement of what a department, college or university holds to be important. It is meant to inspire and encourage commitment to stated ideals and help develop appropriate attitudes across campus. Two versions of a proposed creed, a long and short version, are presented.
\end{abstract}

\section{INTRODUCTION}

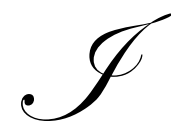

$\mathrm{n}$ recent years, the accounting profession has suffered from a steady stream of highly publicized scandals. The names of companies such as Enron, WorldCom, Global Crossing, Health South, Adelphia Communications, and Tyco serve as a shorthand expression for the ethical lapses exhibited by management and, in some cases, the CPA firms responsible for auditing their financials. Shareholders, creditors, employees, and others harmed by corporations engulfed in scandal or bankruptcy bear witness to the severe financial and emotional toll resulting from the actions of managers and insiders who lack character. 
To some degree, all educational institutions consider the importance of character. Character traits of prospective students are considered as part of the process of admitting students and awarding scholarships. The nation's military academies make developing character a priority. Most private and faith-affiliated colleges and universities are concerned with character as a general educational objective. Partially in response to recent scandals in business, government, and sports, many public colleges and universities have added courses in ethics or augmented courses with ethics exercises or cases.

In recent decades, most accounting curricula have included ethics assignments in a variety of courses. However, recent lapses in personal and professional judgment by the auditors of the above companies suggest the need for a renewed emphasis upon promoting and developing character and ethical behavior in accounting majors.

Educational institutions compete with one another for funds, faculty, and students. These resources are the ingredients that will determine the quality of outcomes from teaching, research, and service. Alternatively, public and private sector employers are not only concerned with knowledge and skills acquired by college graduates, but are just as interested in their character as well. Most references (both written and oral) supplied by faculty and others for graduates are essentially character-based testimonials. Employers are interested in character because they recognize that the strength of these personal attributes is an important determinant in their organizations' success.

In this article, the term "character" is first defined. The issue "why character counts" is next explored and is followed by methods by which educational institutions can promote positive character traits among its students, faculty, and administrators. An institutional creed --known as a university creed-- is next introduced. It should be noted that this creed is adaptable for use by various university units (including departments, colleges, and divisions). Finally, other considerations involving the adoption of a creed are explored and two examples are presented.

\section{CHARACTER DEFINED}

Today, public institutions of higher education emphasize, among other things, the development of problem solving or critical analysis skills. These skills include: 1) recognizing potential or current problem areas, 2) developing problem-solving strategies, 3) determining the type of and the proper amount of resources to be used in support of a proposed strategy, 4) executing a chosen strategy, 5) defining, developing, and using appropriate systems to measure progress towards problem resolution, and 6) adjusting the chosen strategy if needed. However, only a few institutions devote identifiable resources to promoting positive character traits among their students.

Webster's $21^{\text {st }}$ Century dictionary defines character (p. 48) as: 1) moral strength, 2) person as judged by his actions, and 3) reputation. Integrity (p. 141) is defined as the "firmness of character," that is, the relative degree of character. Character is comprised of the breadth and depth of personal traits. In a strategic and operational sense, these traits include:

1. Honesty (the ability to admit mistakes in a timely fashion regardless of personal expense; not taking possession of anything tangible or intangible that belongs to someone else).

2. The ability to develop loyalty and to be loyal (typically generated by the recognition of one's concern for the welfare of others).

3. Courage (the conviction to take professional risks; to give voice to an unpopular opinion).

4. Perseverance (the ability to overcome failures and endure criticism; the extent of one's endurance and commitment).

5. A servant's attitude (exemplified by behaviors that don't maximize individual gain or gain for only a few but emphasize advancement of the organization as a whole; helps control selfishness and greed).

6. Humility (the willingness to embrace the ideas of others; not promoting one's self or empire building; having an attitude of giving to as opposed to taking from or pillaging an organization; helps reduce pride).

7. Passion (enthusiasm for the struggle; intangible drive; the internally motivated self discipline needed to accomplish the task). ${ }^{2}$ 
Character is a larger concept than any one of these traits. It encompasses the concepts of integrity and ethical behavior. Persons of character not only possess many or most of the above traits but they use them as decision and behavioral norms (standards) in strategy development and execution. If one word could express the meaning of character, that word might be - Attitude.

\section{WHY CHARACTER COUNTS}

Character drives personal and professional behavior. Negative character traits such as greed, pride, envy, egotism, a controlling spirit, and unchecked ambition can drive decisions that ultimately reflect unrestrained selfishness or self-obsession (Gaebelein and Simmons, p. 163). For example, a golden parachute is often selfdetermined or cozily negotiated by individuals or small, self-proclaimed elite groups. These types of financial arrangements, often extremely generous, ensure certain levels of compensation during or at the end of one's career. No organization is exempt from such behavior by executives or key personnel. ${ }^{3}$

Another negative character trait is unbridled ambition. This trait can cause organizational disruption, employee malaise and distrust. For example, a strategy for organizational advancement used by some individuals may be based not only on merit but also on a variety of questionable practices. Such practices might materialize as communication strategies that are employed to influence others (a form of empire building). These strategies might include message or information control, communication intended to control or discourage colleagues, deceptive/manipulative interactions, and unwarranted criticism of others to superiors. These types of relational interactions are attempts to disrupt and redefine superior-subordinate or subordinate-subordinate relationships for personal gain (Lee, pp. 181-185).

Today's lexicon includes such terms as "take no prisoners," "slash and burn," and "show no mercy." Unfortunately, these terms can describe attitudes towards individuals inside as well as individuals or entities outside an organization. In such an environment, watching one's back and infighting becomes first priority instead of advancing organizational goals. Individuals may use others as instruments to further their ambitions and enhance their own status. Many individuals operationalize the philosophy of "if it's not illegal, then we will do it," trying to out-deceive or out-justify others in order to maximize their self-interest. Leaders and employees who use such strategies have profound character choices to make (Gaebelein and Simmons, pp. 10-11). In the final analysis, integrity and ethical behavior standards will reflect the attitude of leadership. Positive or negative character traits will drive leadership. Individually, we might consider taking inventory and analyzing those needs and attitudes that drive our professional strategies and relational tactics. We would do well to promote, at times, something beside ourselves.

The team approach, the current problem-solving and instruction paradigm utilized by most organizations (including educational institutions), works best when team members have and display positive character traits. Organizations treasure employees who work effectively, with no personal agenda, with other employees to solve problems.

Today's world is highly competitive and ever-changing. Organizations often find that even with problemsolving competencies, adequate technologies, and proper capitalization, it is still difficult to reach those objectives that the market place demands. The ingredient that often spells the difference between expected, average or mediocre results is the character of involved employees. Organizations need leaders and employees with strong character traits.

Leaders and employees of good character are secure in themselves, share knowledge and expertise, are concerned about the welfare of others and practice self-discipline. Self-esteem is not based on personal accolades or exposure, position privilege, or a deliberately cultivated reputation. Such persons are not threatened by the talent or success of others. They do not attempt to take possession of or control all processes. They encourage others to use their creative and managerial talents. By delegating decision-making authority, these leaders make themselves vulnerable through accepting the risk of failure. These attributes create a work place where people want to work, as opposed to have to work (Gaebelein and Simmons, pp. 16-20). 
When individuals of good character combine talents, organizations may achieve extraordinary results. Positive character often generates the value-added, the synergy, and the competitive advantage that organizations seek. Character creates energy which generates creativity, which, in turn, produces high levels of innovation and productivity. This form of energy can be sensed and felt. Leaders and employees have a gleam in their eyes that denotes purpose, conviction and passion. Success does not depend on a superhuman effort by leadership. Alternatively, good leaders understand that their futures are in the hands of their subordinates, and they act accordingly. People, not technology, are an organization's ultimate resource (Gaebelein and Simmons, pp. 17-19).

Positive character will help reduce the walls of mistrust that sometimes exist between individuals. Understanding differing points of view and the needs of others should be a priority. Character simply resonates with most people. Evidence exists that organizations that promote and encourage decision-making based on character virtues prosper beyond expectations because they create and promote internal and external trust.

Educators realize that students learn from what they hear, from what they see, and from what is practiced. Environment impacts students' attitudes. How will students react when they are under stress and performance pressure exists? For example, if students see other students successfully cheating or become aware of faculty or administrators fudging numbers to meet career objectives or compete for resources, their reaction might be that such behavior is acceptable and part of the institution's culture. However, these types of behaviors are morale and incentive killers. They undermine a student's (employee's) confidence in the concept of fairness (a level playing field), trust in leadership (management), and due diligence on the part of faculty (a student's immediate superior).

Unless strong beliefs and values already exist, many students will find it difficult to resist the herd mentality when moral and/or ethical dilemmas occur in their academic or professional careers. Students should understand that how they pursue their goals will eventually catch up with them. In the long run, the content of one's character will, at least in general terms, be revealed.

The promotion of character by educational institutions (and its units) is not promoting goodness for goodness sake. It is not the introduction of naïve, weak, or Pollyanna-like assumptions into one's decision-making process. The above character traits demand intelligence, conviction, and fortitude. In essence, positive character is the foundation from which true self-esteem germinates, providing a basis for constructive self-governance. Character pushes one forward in search of fulfillment. History is replete with examples of character impacting the outcome of events.

\section{INSTITUTIONAL CONTROL SYSTEMS}

Given that constituents external to educational establishments recognize the importance of positive character, how can educational institutions promote these traits? One's character is substantially shaped by the time a person attends college. Character traits are influenced by family, cultural, institutional, and personal experiences and may not be easy to change. However, student attitudes and decisions can be influenced by their perception of institutional standards of behavior. It is important that administrative officials and faculty display character. Beyond their examples, educational institutions have two types of control systems to foster expectations and influence behavior: beliefs and boundary systems (Atkinson, Banker, Kaplan, and Young, pp. 20-24).

A belief system is a set of documents that explicitly state, in a positive fashion, the direction, purpose, and values of an institution and its units. Documents in this system include institutional and unit vision and mission statements, creeds, and mottos. Vision and mission statements communicate purpose and direction. Both statements should reinforce the notion that character is an essential priority in the educational process. A belief system attempts to change the orientation of one's thought processes thus influencing the choice of behaviors in personal strategy formulation and execution.

Institutional boundary systems consist of a set of explicit statements that communicate, in a negative fashion, those behaviors students must not engage in and the penalties or consequences of violations. These statements must clearly communicate society's laws as well as institutional expectations and sanctions. Processes 
must be in place for enforcement purposes. Statements in this system include codes of conduct, honor codes, environmental, health and safety pronouncements and pronouncements concerning zero tolerance for sexual harassment, racial and gender discrimination.

\section{INSTITUTIONAL CREED}

In order to promote values and expectations, some public institutions of higher learning have embraced the credo or creed. ${ }^{4}$ Webster's defines a creed (p. 71) as a "formal stated belief." Unlike a boundary system statement, an organizational creed is a belief system statement which requires no judicial action if its tenets are breached. A creed is simply a statement of institutional beliefs and principles. In essence, a creed is a condensed, positively written statement of the institution's expectations of its students, faculty, and staff. Many individuals, particularly external to an institution, are not familiar with the contents of an institution's mission or vision statements. A creed is a public pronouncement of what the institution holds to be important. A creed is meant to inspire students and encourage commitment to the institution's mission, vision, and ideals. It will publicly reveal much about an institution's aspirations.

Communication of a creed's tenets is vital if a college or university wants to promote the development of a campus culture of character or other priorities. Otherwise, a creed will only be organizational window dressing. There are several ways to communicate to students and others the contents of this statement (The Carolinian Creed Its Origin, p. 3). A creed can be 1) reviewed and interpreted for students in orientation courses, 2) incorporated as part of course syllabi, 3) displayed in foyers of buildings and in classrooms, 4) displayed on promotional material, and/or 5) promoted at special institutional events. These are inexpensive yet effective methods to promote creed tenets.

\section{THE NEED FOR A CREED}

Is there really a need of an institutional statement of beliefs promoting character and other ideals such as scholarship (excellence in teaching and learning)? When anecdotes concerning student behavior, achievement, and academic integrity are compared among colleagues from other institutions, the conclusions reached are usually the same. Today, a significant proportion of students are not prepared either academically, behaviorally, or motivationally for the college or university experience.

The first priority of students should center on scholarship (learning), the acquisition of knowledge and skills, and learning how to learn. Many students arrive on campus well prepared. These students take advantage of opportunities offered in preparation for their careers or future studies. Colleges and universities justifiably should recognize and promote the achievements of these students.

Other students, whether attending flagship universities or two-year colleges, arrive possessing varying degrees of academic preparation and aptitudes along with a wide range of attitudinal dispositions. Some of these students are academically prepared or possess innate intellectual ability but are behaviorally immature. Some understand behavioral standards but are not academically prepared. Many students are motivated to excel regardless of the obstacles they must overcome. Others display little inspiration, inclination, or appetite to meet challenges that come their way. Some students arrive with an ingrained sense of entitlement, and inappropriate behavior frequently results from this attitude. Students often believe that faculty will conform to their expectations.

Today, the lack of academic integrity on U.S. College and university campuses poses its own set of problems. One either cheats on tests and assignments, plagiarizes written work, or one chooses not to. Burnett (2002) reviews the work of McCabe and Trevino who document the decline of academic integrity using research dating from 1963 through 2002. McCabe and Trevino (p. 41) also document the trend of academic integrity violations on campuses with honor codes verses campuses where no codes exist. They believe that moral development can advance dramatically over a student's college years. 
For example, academic integrity, not surprisingly, can be significantly influenced when a student is in an environment that values honesty. Alternatively, academic dishonesty will be encouraged when there is a perception such behavior is widespread.

Honor codes are grounded in a sense of community responsibility for academic integrity. In particular, honor codes attempt to change campus culture by convincing students that cheating is not socially or morally acceptable. Research suggests that, in general, institutions with existing strong (enforced) honor codes have fewer incidents of cheating than institutions without codes simply because of greater campus-wide disapproval. However, institutions without codes have also been successful in reducing academic dishonesty. Administrators at these institutions have followed the basic strategy of: 1) communicating the importance of and commitment to academic honesty campus-wide and 2) promoting discussions among all campus constituents to emphasize the notion that every member of the community is responsible for academic integrity. Unfortunately, the development of a shared campus culture of honesty is more difficult to achieve when many students live off-campus, attend classes part-time, and/or do not participate in extracurricular campus activities (McCabe and Trevino, pp. 40-41).

Why do students cheat, plagiarize, or unethically collaborate with one another? Discussions with students have revealed the following reasons (not in order of justification):

1. Given other class requirements, employment, and social activities, students simply run out of time to complete their assignments or prepare for tests.

2. Students don't believe that they will get caught and even if they do, they believe that most faculty members don't want to go through the administrative hurdles to press their case.

3. There is great parental pressure for good grades in order to keep scholarships and to gain family recognition.

4. Some students are just too lazy and irresponsible to do what is necessary to earn good grades.

5. Some students enjoy inventing ways to beat the system; they cheat for the fun and thrill of it.

6. Many scholarships, such as the Hope Scholarship in Georgia, require the maintenance of a given GPA.

7. Students are concerned about the impact that grades have on potential employment or graduate school admission.

These discussions also revealed ingenious ways to cheat. ${ }^{5}$ In addition, the availability of the World Wide Web facilitates widespread selling of research papers on almost any topic. The use of whole or parts of purchased papers cannot be resisted by many students. When students plagiarize or cheat, they don't establish or perfect their own individual learning processes and styles. They do not master basic knowledge in their fields of study. Career and life preparation suffer. These students have decided to develop and execute inappropriate strategies for meeting their objectives. Their beliefs and attitudes will most likely have a negative impact on decisions in other areas of their lives as well.

In response to the above circumstances, the text of classroom policies incorporated in course syllabi have dramatically increased. A great deal of faculty time and energy, both in and out of class, is now consumed by classroom management activities. However, some students resent policies that ensure classes will be conducted in an orderly and appropriate fashion. Some even believe that faculty are "out to get them." Students often expect faculty to teach the exact contents of a test. Faculty respond by using more constrained or formal teaching approaches.

Belief system statements such as an institutional creed are meant to define and instill positive attitudes, foster expectations, and inspire students. While an institutional creed may be instrumental in the development of a desired campus culture, academic dishonesty and inappropriate behaviors should be confronted using boundary system statements such as honor codes and faculty and institutional follow-through. Changing campus culture is a long-term process. The simultaneous use of both belief and boundary system statements might hasten the development of more mature campus attitudes. 


\section{USE OF CREEDS BY OTHER ACADEMIC UNITS}

As mentioned earlier, the university creed is adaptable for use by its various units. A division, department, or college may find it beneficial to adopt its own creed. In a Zogby poll conducted in 2002 --published by the National Association of Scholars-- three quarters of business and accounting majors surveyed indicated "they are taught that right and wrong depend 'on differences in individual values and cultural diversity"'. (See Accounting Scandals Start at Varsity, by Tim Wood, posted on Moneyweb website (7/5/2002)). Only one quarter of those surveyed indicated being taught that "clear and uniform standards of right and wrong [exist] by which everyone should be judged". [Id.].

If, as the National Association of Scholars claims, the trend at universities is towards "the relativization and politicization of ethical standards", then a creed adopted by a Department of Accounting or a College of Business may be useful in helping each student develop his or her "moral compass".

In addition, adopting such a creed is entirely consistent with the recent memorandum from the Ethics Resource Center Fellows to the AACSB regarding proposed standards and business school responsibilities. [See Ethics Education in Business Schools (Draft Proposal), Ethics Education Task Force of AACSB International $(2 / 3 / 2004)]$. In this memo, the ERC Fellows stated, "the AACSB should have the courage of its convictions and require not only the inclusion of business ethics in separate courses but also evidence that schools of business are making a concerted effort to develop the ethical competency of their students in core areas of the business curriculum." [Id.].

\section{REASONS STUDENTS MIGHT REJECT CREED TENETS}

The active promotion of character and other institutional priorities may not be well received by some students. These individuals may view such promotion as silly or an unwarranted attempt to alter their behavior. Some students may feel that the practice of positive character will not generate adequate results in the academic or the outside world. They believe that the integration of character into decisions undermine their ability to be competitive in a market driven and result-oriented culture. Institutions need to find ways to demonstrate that this attitude is indicative of short-run thinking. Students must realize that the promotion of positive tenets surrounding character, scholarship and performance in the college or university environment will increase their chances of long run success.

\section{CREED DEVELOPMENT}

The development of an institutional creed emphasizing character and other priorities may be a laborious process. Administrative officials and faculty should recognize both the benefits internally and externally that will accrue to the institution through the identification and promotion of organizational values and beliefs. They should recognize the fact that a statement of ideals is beneficial simply because it serves as a continuous reminder to students and employees of those things that are important to the institution. Such a statement will reinforce core organizational values. Outside parties will have tangible evidence of the institution's commitment to stated ideals. The enthusiasm demonstrated by administrators and faculty for this form of ideals expression will determine whether this type of project is undertaken and the time frame of its implementation.

Given administrative and faculty approval and commitment, creed development responsibility will likely be assigned to a specially constituted committee. A person of influence inside the institution who has real enthusiasm for the project should chair this committee. ${ }^{6}$ Committee members include alumni, students, staff, faculty, and the representatives of the surrounding community. If possible, these individuals should be opinion leaders.

Using input from constituent groups, this committee will fashion the contents of the statement and develop its form and title. Committee members should realize there is no magical template to fashion a creed. A creed should address global institutional needs, priorities, and desired outcomes. It is also important that creed tenets be written in an understandable and straightforward fashion so all constituent parties, including students, understand them. 
Approval of a final statement should be sought from the institution's advisory board, board of trustees, administration, and constituent groups (The Carolinian Creed - Its Origin, p. 3).

\section{CREED EXAMPLE: LONG FORM}

An example of a creed promoting character, scholarship, and performance can be found in Appendix A. Scholarship is included because it is a basic outcome that academic institutions - and their units - promote. Performance is also included because we are all measured by the extent of the contributions we make to our employer organization and to the betterment of society. The tenets in this example creed include explanations, therefore, no statement of tenet justification and description is provided.

\section{CREED EXAMPLE: SHORT FORM}

Some institutions may prefer to use a creed containing only fundamental values, priorities, and ideals. An example of such a creed can be found in Appendix B. In Appendix C, a statement of tenet justification and description offers explanations and examples of behaviors, beliefs, and principles consistent with creed tenets.

\section{CONCLUDING COMMENTS AND SUGGESTIONS FOR FUTURE RESEARCH}

As human beings, we all work for economic independence, recognition, and influence. Many students choose to work hard in order to acquire the knowledge and skills they will need to compete and be successful in our society. The character struggle occurs daily as we make routine and non-routine decisions. We consciously or subconsciously compare strategies to reach objectives. Different strategies will cost different amounts of resources, energy, and time. We determine the likelihood that a particular strategy, given the hurdles we must overcome, will lead to a given degree of success (however we define success). Character will influence the rigor and types of objectives and strategies we develop. Character will determine those behaviors chosen to execute a selected strategy. Often character inclusion in decision-making will lead to a longer, more difficult road to objectives. However, at the end of the day, if a person's character drives an appropriately developed strategy and its execution, most objectives will be met. ${ }^{7}$

Future research may explore how, as educators, we can promote character virtues in our students in the same fashion (lecture, readings, group practice cases, and discussion) we promote scholarship. The recognition and promotion of good character should be as important an institutional priority as scholarship and performance. If faculty members at the institution level are not willing to address character issues in some form, the leadership of public university systems should seriously consider addressing the matter. Future research may help us discover if our students have better skills, abilities, as well as character when they leave us compared to when they came to us.

Future research may also help us to discover ways to integrate character virtues into the decision making process of students. A person may be neutral to or reject such virtues for reasons that appear justifiable to that individual (Gaebelein and Simmons, p. 7). One may be captive to long established routines, traditions, or patterns of thinking and behavior. Or, a person may choose to embrace such virtues and obtain advantages in personal and professional endeavors. Whether that choice is spiritually driven or driven by the recognition that character is an important element in success will depend on the individual. At some point in a person's development, the practice of inclusion of positive or negative character in decision-making and behavior will become a model of how one approaches life after graduation. Character promotion by public institutions of higher learning (and their units) will help to develop men and women who have the courage to take responsibility, accept accountability, and place the welfare of an organization and its employees first. 


\section{APPENDIX A: UNIVERSITY CREED - LONG FORM}

\section{Character}

1. We believe in personal and academic integrity. We believe in honesty, truthfulness, self-reliance, selfcontrol, and hard work.

2. We believe in courage and action in the face of adversity. We refuse to play the role of victim because we believe in and respect ourselves.

3. We believe we should obey the rules and regulations of the institutions we are a part of and the laws of the country in which we live in order that the rights of others will be protected.

4. We believe in serving, sharing, humility, tolerance, and respect for all persons because this creates an environment that encourages mutual learning, growth and success.

5. We believe that these personal traits, in the long run, will help us gain the respect and confidence of our associates.

\section{Scholarship}

1. We believe in scholarship, the study of systems, events, cultures, doctrines, and values of the past and present because such investigation can help us understand humankind's circumstances today and help us personally adapt and improve humanity's condition in the future.

2. We believe that scholarship occurs as an interactive process between faculty, students, and other interested parties. Learning, which ultimately culminates in wisdom, happens when all parties dedicate themselves to the process of transference, reception, and synthesis of facts, knowledge, and ideas.

3. We believe in mastery of communication, critical thinking, and technical skills required in a complex world so we can discover and utilize those special gifts that each of us alone possess.

4. We believe scholarship will help reduce self-centeredness, soften our hearts, and help us connect with others, thus making us more complete and balanced persons with broader perspectives in our professional and personal relationships.

5. We believe that scholarship will enable us to work more wisely, more effectively, and more efficiently in a competitive world and, in the long run, will better equip us to take our place in society and help us discharge our leadership responsibilities.

\section{Performance}

1. We believe performance is the result of understanding natural and human-made processes and the motivation and passion to improve these processes.

2. We believe that we must periodically explore our motivations because they inevitably determine our direction, level of effort, and behavior.

3. We believe performance should not only be characterized as "goal achievement," but as importantly, by the notion of developing practical, workable solutions to complicated problems.

4. We believe all human beings have flaws and experience failure. However, we believe in the constant and continuous renewal of effort, perseverance, and improved performance, which often stems from the lessons we learn from our failures.

5. We believe that if we strive for that level of performance that is at least commensurate with our gifts and talents, in the long run, our individual and collective condition will improve. 


\section{APPENDIX B: UNIVERSITY CREED - SHORT FORM}

As members of the community of this institution, we will strive to provide educational excellence in a secure, sharing, and tolerant environment. We believe that honorable, civil, and dedicated behavior on the part of all community members will help achieve this goal. These behaviors, which have their foundation in character, are also essential in developing an environment conducive to scholarly activity, learning, and true achievement.

\section{We Believe A Balanced Institutional Culture Should Reflect...}

- $\quad$ Personal and academic integrity; courage and action in the face of adversity; and humility, a serving and caring attitude, and respect for all persons.

\section{We believe scholarly activity and learning...}

- $\quad$ Should be the first priority of administrators, faculty, students and staff; should be driven by a desire for self-sufficiency; and is a product of open and uninhibited communication.

\section{We believe true achievement...}

- Is the result of rigorous preparation, dedication, and perseverance; potentially includes some degree of introspection; and can result from the lessons we learn from failures. honor it.

Since (your institution) promotes the ideals and principles of individual development, we will respect and

\section{APPENDIX C: TENET JUSTIFICATION AND DESCRIPTION}

As members of the community of this institution, we will strive to provide educational excellence in a secure, sharing, and tolerant environment. We believe that honorable, civil, and dedicated behavior on the part of all community members will help achieve this goal. These behaviors, which have their foundation in character, are also essential in developing an environment conducive to scholarly activity, learning, and true achievement.

...this introductory statement describes an institutional goal and three character-based behavioral attributes needed for goal attainment. It is expected that these behavioral attributes will help develop a balanced institutional culture where scholarly activity can flourish and varied learning experiences can take place. This environment should produce true achievement in many individual and group activities. If all community members continuously strive to behave in an ethical and meritorious fashion, they will fulfill their institutional obligation.

\section{We believe a balanced institutional culture should reflect...}

- $\quad$ personal and academic integrity;

...this ideal promotes the belief that true personal and institutional advancement is not possible if one cheats lies, steals the property of others, plagiarizes, uses the work of other students, or refuses to take responsibility for one's actions. Engaging in inappropriate relational practices such as interactions intended to control, discourage, manipulate, or deceive or interactions that jeopardize the reputation of others is wrong. This tenet emphasizes honesty with oneself and others, self-reliance, self-control, and hard work...

- $\quad$ courage and action in the face of adversity;

...adversity implies an unfavorable outcome, event, or condition. It may be, among other things, poor grades, a family death, parental divorce, the loss of employment, poor physical or mental health, overwhelming personal and/or professional responsibilities, or intolerance in one's living and/or work environment. Courage and action 
implies gathering ourselves in such times and taking stock of our resources and circumstances. We will, to the best of our abilities, develop and execute appropriate strategies in order to overcome the difficulties we face in life. This tenet emphasizes the fact that we refuse to play the role of a victim because we believe in and respect ourselves...

- Humility, a serving and caring attitude, and respect for all persons.

...humility reflects an attitude of gratefulness and is associated with giving credit to others who deserve recognition. True humility reduces pride. Serving and caring represent an attitude of giving to as opposed to taking from an individual or the institution. These two attitudes serve to advance the interest of others and that of the institution. Demeaning behaviors such as ridiculing or making fun of an individual lower the dignity and self-esteem of all parties involved. This tenet promotes an environment of sensitivity where individuals can feel secure and grow intellectually and emotionally.

\section{We believe scholarly activity and learning...}

- $\quad$ should be the first priority of administrators, faculty, students and staff;

...towards this end, many people work hard to ensure that a large number of elements smoothly integrate or exist to produce a superior educational experience. These elements include such things as student and institutional support systems, the availability of technologically advanced facilities, student extracurricular opportunities, and an attractive campus environment. These and other elements provide the setting that supports an institution of higher education in fulfilling its basic mission of quality faculty and students engaging in scholarly activities to produce varied forms of learning...

- $\quad$ Should be driven by a desire for self-sufficiency;

...scholarship involves the rigorous study of natural and artificial systems, events, cultures, doctrines and values of the past and present. Such investigation can help one understand humankind's present circumstances. This understanding should help an individual prepare for the challenges of the future. This tenet directly encourages mastery of communication, critical thinking, and technical skills required for success in a complex and changing world. In this manner, one can become self-sufficient and hopefully experience economic freedom. Scholarship and learning will ultimately culminate in wisdom...

- Is a product of open and uninhibited communication.

...communication, whether oral, written, or demonstrative is a form of behavior. One's communication should reflect respect for the dignity and rights of all individuals whatever their beliefs or station in life. Being members of a culture that promotes the exchange of ideas and opinions, we believe that all constituents of this institution should be guaranteed the basic right to civilly express themselves without fear of personal or professional reprisal or penalty. Today's ideas and opinions often become tomorrow's facts and reality.

\section{We believe true achievement...}

- $\quad$ is the result of rigorous preparation, dedication, and perseverance;

...true achievement in any endeavor requires personal discipline and courage to continue after failure(s). Achievement requires a relentless spirit to "get it right" and an attitude of continuous improvement that assumes "it is never exactly right." True achievement will exact a price, an expenditure that can be measured in time, effort, and financial terms. If one is prepared to fully utilize his/her talents and resources in an organized fashion and gives a total and complete effort, the resulting mark achieved, regardless of its position on a given scale, is true personal achievement... 
...one's contribution to the achievement of team goals requires similar individual sacrifice. In addition, one must surrender individuality. Team or group achievement results from synergy of positive attitudes and maximum efforts. For many individuals, however, the seduction of achievement, whether individual or team based, will create new challenges...

- $\quad$ potentially includes some degree of introspection;

...while it is important to understand the fact that effort is required to fulfill one's potential, it is essential to emphasize the fact that growth, a precursor to achievement, is often dependent on the recognition, the admission, and the effort expended to correct dysfunctional personal and/or professional attitudes or behaviors. For example, one would not cheat or plagiarize when sincerely searching for or developing the academic talents and gifts one wishes to possess. A distance runner will not consume drugs harmful to mind or body because such consumption is goal defeating. A rational person will not drive an automobile when intoxicated. This process requires honest, individual labor of a different kind. Continuous individual or team achievement is rarely possible unless selfdefeating attitudes and behaviors are rectified...

- $\quad$ Can result from the lessons we learn from failures.

...everyone experiences failure. Failure is part of the growth experience. However, failure is generally traceable to, among other things: 1) lack of discipline or effort;2) misjudgments of conditions, circumstances, or people; 3) lack of expertise; and 4) the consequences of self-centered behavior. If honestly explored, failure will reveal those conditions and behavior that must be corrected to attain goals. The path to success can be found in failure.

\section{REFERENCES}

1. Atkinson, Anthony A., Banker, Rajiv D., Kaplan, Robert S., and Mark S. Young, 2001. Management Accounting, Prentice-Hall, Upper Saddle River, New Jersey, $3^{\text {rd }}$ Edition.

2. The Auburn Creed, Auburn University, Auburn, AL. http://www.auburn.edu/main/ auburn_creed.html.

3. $\quad$ Burnett, Sara, 2002. "Dishonor and Distrust: Student Plagiarism is Now as Easy as Pointing and Clicking." Community College Week 8 July: 6. Ebsco Host. Ingram Library, State University of West Georgia, Carrollton, GA. http://www.westga.edu/ library/.

4. The Carolinian Creed, The University of South Carolina, Columbia, SC. http://www.sa.sc.edu/creed/.

5. The Carolinian Creed-Its Origin, The University of South Carolina, Columbia, SC. http://www.sa.sc.edu/creed/itsorigin.htm.

6. Gaebelein, Thad A., and Ron P. Simmons, 2000. A Question of Character, Red Book Press, Long Island City, New York, $1^{\text {st }}$ Edition.

7. Lee, Jaesub, 1998. "Effective Maintenance Communication in Superior-Subordinate Relationships", Western Journal of Communications, V 62 (2), pp. 181-208.

8. McCabe, Donald and Linda K. Trevino, 2002. "Honesty and Honor Codes", Academe, (Jan/Feb), V88 (1), pp. 37-41.

9. Webster's $21^{\text {st }}$ Century Dictionary, 1992. Editor: Walter C. Kidney, Thomas Nelson Publishers, Nashville, Tennessee.

\section{ENDNOTES}

${ }^{1}$ The traits of good character were taken from A Question of Character by T.A. Gaebelein and R.P. Simmons. They are not uniformly listed as such but are first developed as themes and then each trait is explored as a topic of character. The authors of this article developed the descriptions for each trait.

${ }^{2}$ We are all economic creatures. Most of us are motivated by what money can do for us. Ideally, we should be compensated according to the quality and quantity of our achievements. However, the use of self-serving strategies to mask, deceive, or manipulate issues such as compensation (often at the expense of others) may have dire consequences for an organization. 
${ }^{3}$ For example, the University of South Carolina developed and actively promotes the tenets of The Carolinian Creed. Auburn University has a credo entitled The Auburn Creed. Johnson and Johnson, the well-respected pharmaceutical firm, developed at length, published, and uses its own credo of responsibilities. Senior managers regularly meet with employees, customers, representatives of local communities, and shareholders to interpret these responsibilities (Atkinson, Banker, Kaplan, and Young, p. 22).

${ }^{4}$ Notes may be written on hat bills, arms, hands, legs, under socks, or on scantron answer forms. Students sometimes use cell phones to text message information and calculators and beepers to store formulas. The plain, oldfashioned cheat sheet is of course used for information storage for in-class tests. "Eyes that wander" appears to be a measure of last resort.

${ }^{5}$ Agreement among institutional constituents concerning the tone and contents of creed tenets is often difficult to achieve. Constituent groups or individual committee members may even attempt to sabotage the project if some version of their view is not incorporated into the creed. Committee organization, the type and number of subcommittees needed, and voting procedures, among other things, should be predetermined. The chairperson most likely will "stand in the gap" negotiating, reconciling, and cajoling committee members as the document is developed.

${ }^{6}$ Our culture is ambivalent concerning many life issues. Fortunately, for the most part, success is not universally defined. Each individual has his or her definition of success. A famous recording by "ole blue eyes" (Frank Sinatra) popularized the phrase "I did it my way." When today's students reach that stage of life when their hair is turning gray, may they revel not in the fact that "they did it their way," but to the best of their abilities, "they did it the right way." To accomplish this ultimate achievement, one may have to build a character fence of deep convictions around one's mind, heart, and emotions.

\section{NOTES}


${ }^{1}$ The traits of good character were taken from A Question of Character by T.A. Gaebelein and R.P. Simmons. They are not uniformly listed as such but are first developed as themes and then each trait is explored as a topic of character. The authors of this article developed the descriptions for each trait.

${ }^{2}$ We are all economic creatures. Most of us are motivated by what money can do for us. Ideally, we should be compensated according to the quality and quantity of our achievements. However, the use of self-serving strategies to mask, deceive, or manipulate issues such as compensation (often at the expense of others) may have dire consequences for an organization.

${ }^{3}$ For example, the University of South Carolina developed and actively promotes the tenets of The Carolinian Creed. Auburn University has a credo entitled The Auburn Creed. Johnson and Johnson, the well-respected pharmaceutical firm, developed at length, published, and uses its own credo of responsibilities. Senior managers regularly meet with employees, customers, representatives of local communities, and shareholders to interpret these responsibilities (Atkinson, Banker, Kaplan, and Young, p. 22).

${ }^{4}$ Notes may be written on hat bills, arms, hands, legs, under socks, or on scantron answer forms. Students sometimes use cell phones to text message information and calculators and beepers to store formulas. The plain, oldfashioned cheat sheet is of course used for information storage for in-class tests. "Eyes that wander" appears to be a measure of last resort.

${ }^{5}$ Agreement among institutional constituents concerning the tone and contents of creed tenets is often difficult to achieve. Constituent groups or individual committee members may even attempt to sabotage the project if some version of their view is not incorporated into the creed. Committee organization, the type and number of subcommittees needed, and voting procedures, among other things, should be predetermined. The chairperson most likely will "stand in the gap" negotiating, reconciling, and cajoling committee members as the document is developed.

${ }^{6}$ Our culture is ambivalent concerning many life issues. Fortunately, for the most part, success is not universally defined. Each individual has his or her definition of success. A famous recording by "ole blue eyes" (Frank Sinatra) popularized the phrase "I did it my way." When today's students reach that stage of life when their hair is turning gray, may they revel not in the fact that "they did it their way," but to the best of their abilities, "they did it the right way." To accomplish this ultimate achievement, one may have to build a character fence of deep convictions around one's mind, heart, and emotions.

\section{NOTES}

